\title{
PEMBANGUNAN APLIKASI MOBILE PENGENALAN OBJEK UNTUK PENDIDIKAN ANAK USIA DINI
}

\author{
Muhammad Fadhlan Supriadi ${ }^{1}$, Ema Rachmawati*2, Anditya Arifianto ${ }^{3}$ \\ ${ }^{123}$ Fakultas Informatika, Universitas Telkom \\ Email: ${ }^{1}$ fadhlansupriadi@students.telkomuniversity.ac.id, ${ }^{2}$ emarachmawati@telkomuniversity.ac.id, \\ ${ }^{3}$ anditya@telkomuniversity.ac.id \\ *Penulis Korespondensi
}

(Naskah masuk: 17 November 2020, diterima untuk diterbitkan: 22 Maret 2021)

\begin{abstract}
Abstrak
Penggunaan ponsel sudah sangat erat dengan kehidupaan anak usia dini sehingga menimbulkan beberapa dampak negatif bagi anak usia dini terutama berkurangnya interaksi dengan dunia sekitarnya. Salah satu teknologi yang dapat dikembangkan pada ponsel adalah computer vision. Salah satu penggunaan computer vision adalah object recognition yang memberikan solusi untuk membantu mengenali objek. Pada penelitian ini dibangun sistem pengenalan objek benda di dalam rumah yang diaplikasikan pada ponsel yang diharapkan membantu anak usia dini mengenali benda disekitarnya. MobileNet merupakan salah satu feature extraction yang memiliki kinerja yang baik dan ringan digunakan pada perangkat ponsel. Arsitektur MobileNet terdiri dari layer depthwise convolution dan layer pointwise convolution dalam mengekstraksi fitur. Percobaan ini juga menggunakan arsitektur Single Shot Multibox Detector (SSD) sebagai metode dalam mendeteksi objek. Pre-trained model dari dataset COCO digunakan pada eksperimen, untuk mengenali 20 jenis objek benda di dalam rumah. Dari hasil eksperimen, MobileNetV2 menghasilkan nilai mean Average Precision ( $m A P$ ) yang lebih baik dibandingkan dengan MobileNetV1 dan InceptionV2, yaitu sebesar 99,34\%.
\end{abstract}

Kata kunci: MobileNet, SSD, computer vision, pengenalan objek

\section{THE DEVELOPMENT OF OBJECT RECOGNITON MOBILE APPLICATION FOR EARL Y CHILDREN EDUCATION}

\begin{abstract}
Mobile phone usage has been very close to early childhood life, so giving rise to some negative impact on early childhood, especially reduced interaction with the surrounding world. One of the technologies that can be developed on the cellphone is computer vision. One of the uses of computer vision is object recognition that provides solutions to help to recognize objects. This research builds a system for recognition objects inside in house that is developed on a cellphone that is expected to help early childhood recognize objects in the surrounding. MobileNet is one of feature extraction that has good performance and efficient use on a cellphone. MobileNet architecture consists of a depthwise convolution layer and pointwise convolution layer in extracting features. The experiment also uses the architecture of Single Shot Multibox Detector (SSD) as a method of detecting objects. We used MobileNet architecture as a pre-trained model that had previously been trained on COCO datasets, and implement transfer learning for 20 types of objects commonly found inside the house. The experimental result indicates that the mean Average Precision (mAP) of MobileNetV2 could exceed MobileNetV1 and InceptionV2 of 99.34\%.
\end{abstract}

Keywords: MobileNet, SSD, computer vision, object recognition

\section{PENDAHULUAN}

Perkembangan teknologi ponsel berkembang sangat pesat diikuti dengan penggunaan ponsel sebagai platform untuk mengakses informasi. Namun penggunaan ponsel menimbulkan masalah yang lebih luas untuk anak usia dini dengan rentang umur 3 s.d. 6 tahun yang menyebabkan anak usia dini akan menghabiskan lebih banyak waktu berinteraksi dengan ponsel dibandingkan berinteraksi dengan dunia sekitarnya (Haddon, 2013). Computer vision merupakan salah satu area penelitian yang berkaitan dengan teknologi ini yang mengajarkan mesin agar dapat memiliki kemampuan melihat dan mengenal objek (Dua \& Cheng, 2014). Salah satu implementasi dari computer vision adalah Object Recognition atau pengenalan objek.

Dalam beberapa tahun sebelumnya, arsitektur Convolutional Neural Network (CNN) pada 
pengenalan objek telah mengalami perkembangan yang siginifikan. Inception merupakan salah satu arsitektur model jaringan dasar yang memberikan teknik faktorisasi agar ukuran jaringan tidak menjadi terlalu besar sehingga dapat mengurangi waktu pengenalan objek dan mempertahankan akurasi (Szegedy, Vanhoucke, Ioffe, Shlens, \& Wojna, 2016). Akan tetapi, kerumitan pada perangkat ponsel yang memiliki daya komputasi dan sumber daya memori yang terbatas mendorong peningkatan efektivitas model Convolutional Neural Network (CNN) agar dapat berfungsi dengan baik pada perangkat ponsel.

Salah satu model Convolutional Neural Network (CNN) yang dapat dijalankan pada perangkat ponsel dengan kinerja yang baik adalah MobileNet. MobileNet memiliki spesifikasi rendah, latensi rendah, dan daya konsumsi rendah sehingga sangat disarankan untuk diimplementasikan pada perangkat ponsel (Howard, 2017). Perbedaan mendasar antara arsitektur MobileNet dengan arsitektur CNN lainnya adalah penggunaan layer konvolusi dengan ketebalan filter yang sesuai dengan ketebalan dari masukan citra. MobileNet menerapkan arsitektur depthwise separable convolution yang membagi layer konvolusi menjadi depthwise convolution (Wang, Yuan, \& Li, 2018) dan pointwise convolution (Hua, Tran, \& Yeung, 2018) serta dalam pengembangannya telah ditambahkan arsitektur baru yaitu linear bottleneck dan inverted residuals (Sandler, Zhu, Zhmoginov, \& Jan, 2018).

Pada penelitian ini diaplikasikan transfer learning pada model MobileNet yang sebelumnya telah dilatih pada COCO datasets (Lin dkk, 2014) untuk digunakan pada 20 objek benda. Selanjutnya implementasi pada perangkat ponsel menggunakan ML-Kit Firebase sebagai penghubung model dengan ponsel. Aplikasi yang dibangun diharapkan dapat mengedukasi penggunaan ponsel yang baik untuk anak usia dini dalam mengenali objek-objek disekitarnya.

Susunan makalah adalah sebagai berikut. Deskripsi sistem yang diusulkan terdapat pada bagian 2. Eksperimen dan analisis pada bagian 3 dan ditutup dengan kesimpulan pada bagian 4 .

\section{SISTEM YANG DIUSULKAN}

Dalam penelitian ini dibuat rancangan sistem pengenalan objek dengan data masukan berupa citra. Sistem menggunakan MobileNet dengan mengaplikasikan transfer learning pada dataset baru dan Single Shot Multibox Detector (SSD) sebagai metode dalam mendeteksi objek. Secara umum penelitian ini memiliki skema seperti Gambar 1.

Citra masukan akan melalui tahap praproses terlebih dahulu berupa pemberian label bounding box yang akan digunakan pada tahap deteksi. Label ini berfungsi sebagai ground truth bounding box yang menjadi acuan apakah terdapat objek pada citra tersebut.

\subsection{Penentuan Konfigurasi Sistem}

Setelah proses preprocessing dilakukan maka terdapat data berupa citra dan label, namun data tersebut kemudian dikonversi terlebih dahulu sebelum dapat digunakan oleh Tensorflow. Citra yang telah dilabeli memiliki format file xml yang perlu dikonversi ke file berformat csv untuk menggabungkan seluruh file xml ke dalam 1 file pelatihan atau pengujian. Setelah file dikonversi ke format csv, selanjutnya file tersebut dikonversi lagi menjadi file TFRecord di mana file tersebut merupakan format dataset yang dapat digunakan pada Tensorflow. Selain itu membuat file baru label map yang berisi indeks dari 20 objek dataset.

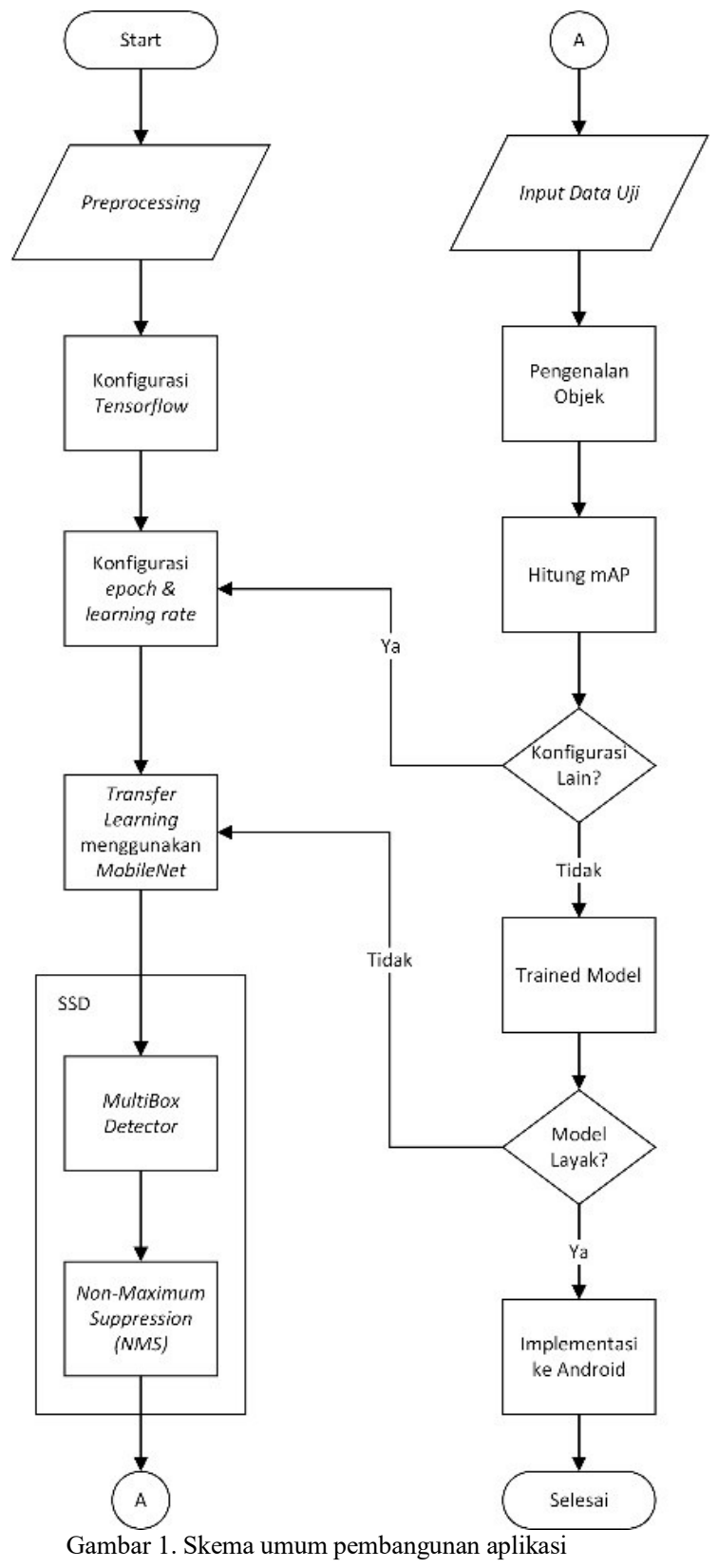

Pada penelitian ini digunakan konfigurasi berbeda-beda. Pada tahap konfigurasi, nilai epoch dan learning rate disetel untuk menguji kombinasi 
parameter yang dapat memaksimalkan akurasi pengenalan objek.

\subsection{Transfer Learning dengan MobileNet}

Pada arsitektur MobileNet (Sandler, Howard, Zhu, Zhmoginov, \& Chen, 2018) terdapat tiga layer konvolusi yang harus dilalui citra dalam mengekstrasi fitur. Batch normalization ditambahkan pada layer konvolusi yang berguna untuk meningkatkan kinerja dan stabilitas jaringan saraf tiruan. Fungsi aktivasi yang digunakan pada MobileNet adalah ReLU6 (Sandler, Howard, Zhu, Zhmoginov, \& Chen, 2018). Dibandingkan dengan ReLU yang biasa, ReLU6 lebih kuat ketika menggunakan komputasi presisi yang rendah tetapi mencegah aktivasi yang terlalu besar.

Transfer learning dilakukan dengan cara menggunakan knowledge yang terdapat pada pretrained MobileNet COCO yang memiliki 91 kelas objek dan 328.000 citra (Lin dkk, 2014). Knowledge tersebut disesuaikan dengan kelas objek yang digunakan saat pelatihan, yaitu 20 kelas objek.

Proses transfer learning dapat dilakukan dengan beberapa langkah, langkah awal dengan menghapus fully-connected layer terakhir dari pre-trained model yang berisi klasifikasi dari 91 kelas objek. Langkah selanjutnya, mengganti lapisan tersebut dengan fullyconnected layer baru yang hanya memiliki klasifikasi 20 kelas objek ditambah dengan kelas background. Langkah terakhir, dilakukan fine tuning yang bertujukan melatih linear classifier sehingga dapat digunakan pada data yang lebih sedikit (Pan \& Yang, 2010).

\subsection{Single-Shot Multibox Detector (SSD)}

Single Shot Multibox Detector (SSD) menggunakan metode MultiBox Detector untuk regresi bounding box dalam menentukan prediksi lokasi objek sekaligus mengklasifikasikannya pada suatu masukan citra. Cara kerja MultiBox Detector adalah dengan menyesuaikan classifier pada setiap layer konvolusi yang berukuran $m * n * b *(4+$ c) dengan $m * n$ adalah ukuran feature map (contohnya $3 \times 3$ yang akan menghasilkan 9 sel atau grid), $b$ adalah jumlah predict bounding box per grid, dan $c$ adalah jumlah kelas ditambah 4 offset untuk ukuran setiap predict bounding box. Ilustrasi dapat dilihat pada Gambar 2. Selanjutnya SSD akan memeriksa apakah ada objek yang dikenali pada setiap grid pada feature map, ketika mendapatkan objek maka SSD akan membentuk predict bounding box baru dengan ukuran rasio yang berbeda-beda dengan jumlah maksimal 6 bounding box pada setiap grid. Adapun isi dari setiap predict bounding box adalah $P C$ untuk probabilitas softmax kelas target, $B x$ dan $B y$ adalah titik tengah pada grid tersebut sehingga tidak akan pernah melebihi nilai lebih dari $1, B h \&$ $B w$ adalah ukuran lebar dan tinggi dari bounding box tersebut, dan $C 1$ hingga $C 21$ nilai skor prediksi tiap kelas (Liu dkk, 2016).

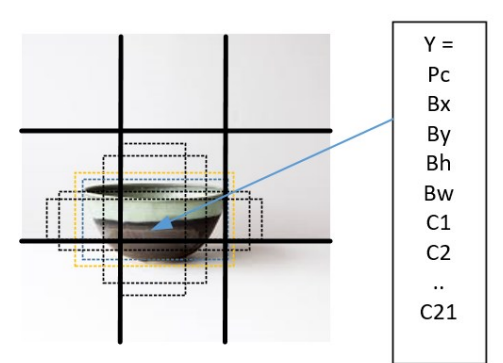

Gambar 2. MultiBox Detector

Metode Non-Maximum Suppression (NMS) membantu dalam mengurangi jumlah predict bounding box pada feature map agar dapat mendapatkan bounding box yang mendekati target kelas objek (Gambar 3). Di tahap awal, Non-Maximum Suppression (NMS) akan menghilangkan seluruh bounding box yang memiliki nilai $P c$ yang kurang dari sama dengan 0,6 , lalu selanjutnya selama masih ada bounding box yang tersisa lakukan 2 tahap berikut: yaitu pilih bounding box dengan nilai Pc tertinggi dan hilangkan bounding box tersisa dengan nilai IoU lebih dari sama dengan 0,5 dengan predict bounding box sebelumnya. Tahap ini dilakukan sampai hanya tersisa satu predict bounding box untuk satu objek pada suatu citra (Hosang, Benenson, \& Schiele, 2017).

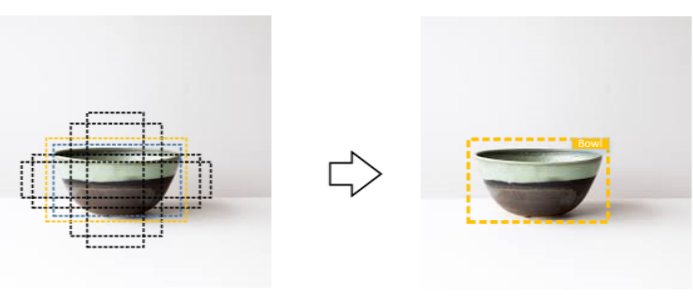

Gambar 3. Non-Maximum Suppression (NMS)

\subsection{Implementasi Model ke dalam Aplikasi Mobile}

Implementasi model ke perangkat android menggunakan Firebase ML KIT yang menyediakan mobile SDK machine learning. Firebase ML KIT membantu agar dapat menghubungkan model yang telah dirancang sebelumnya ke aplikasi yang akan dibangun. Pada Firebase ML KIT dibuatkan project baru serta mengupload hasil ekspor model pada custom model. Selanjutnya pada project android, dibuatkan juga file label baru yang berisi nama-nama objek pada dataset yang disatukan beserta hasil ekspor model ke dalam folder "asset" pada project android.

Aplikasi mobile yang dibangun terdiri dari 3 (tiga) jenis soal berdasar tingkat kesulitan, yaitu:

1. Easy: Aplikasi memberitahu secara langsung label objek yang harus dicari.

2. Medium: Aplikasi memberikan deskripsi singkat tentang objek yang harus dicari.

3. Hard: Aplikasi memberikan gambar bentuk dari sebuah objek yang harus dicari.

Setiap jenis soal terdiri dari 10 soal objek berbeda dengan setiap soal memuat nilai skor 10 ketika 
pengguna berhasil menebak objek tersebut. Setelah 10 soal objek telah dijawab maka aplikasi akan secara otomatis mengkalkulasikan skor akhir yang didapatkan.

\subsection{Pengukuran Kinerja}

Kinerja sistem diukur berdasarkan parameter mAP (mean Averange Precision). Nilai mAP (mean Averange Precision) menunjukkan tingkat pengenalan objek beserta lokalisasinya. Nilai ini menjadi parameter utama untuk mengukur kinerja suatu model yang dirancang dalam mengenali objek. Namun sebelum menghitung nilai $m A P$, Average Precision $(A P)$ untuk setiap objek harus dihitung dulu pada dataset berdasarkan model yang digunakan. Dalam mendapatkan nilai Average Precision (AP) diperlukan juga mendefinisikan True Positives dan False Positivies menggunakan IoU untuk mengindentifikasi apakah deteksi benar (True) atau salah (False). Intersection over Union (IoU) pada persamaan (1) merupakan rasio antara intersection dan union dari ground-truth bounding boxes $\left(\mathrm{B}_{\mathrm{gt}}\right)$ dengan predict bounding boxes $\left(\mathrm{B}_{\mathrm{p}}\right)$ (Rosenbrock, 2017).

$$
\begin{aligned}
& \text { Intersection over Union }(\mathrm{IoU}) \\
& \qquad=\frac{\operatorname{area}\left(B_{p} \cap B_{g t}\right)}{\operatorname{area}\left(B_{p} \cup B_{g t}\right)}
\end{aligned}
$$

Ambang batas IoU yang digunakan adalah 0.5, sehingga jika IoU $>=0,5$ maka akan dianggap True Positive (TP) begitu pula sebaliknya maka akan dianggap False Positivie (FP). Setiap citra memiliki data ground truth yang menunjukkan nilai akurasi prediksi dari objek tertentu pada citra tersebut. Maka dengan $I o U$ dapat dihitung jumlah prediksi yang benar dan prediksi yang salah untuk menentukan Average Precision (AP) pada setiap Class (c) dengan persamaan (2).

$$
\text { Averange Precision }(A P)=\frac{T P(c)}{(T P(c)+F P(c))}
$$

Nilai mean Averange Precision ( $m A P$ ) selanjutnya dihitung menggunakan persamaan (3) (Henderson \& Ferrari, 2017).

$$
\begin{aligned}
& \text { mean Averange Precision (mAP) } \\
& \qquad=\frac{1}{N} \sum_{c \in N} \frac{T P(c)}{(T P(c)+F P(c))}
\end{aligned}
$$

\section{EKSPERIMEN DAN ANALISIS}

Pada bagian ini dipaparkan data yang digunakan pada eksperimen, pengujian pre-trained model pada beberapa arsitektur, hasil pengujian menggunakan beberapa parameter epoch dan learning rate, dan hasil pengujian aplikasi yang dibangun dengan langsung melakukan simulasi langsung pada anak usia dini.

\subsection{Data yang Digunakan}

Data yang digunakan dalam penelitian ini adalah 20 jenis objek yang sering ditemukan di dalam rumah karena akan lebih mudah dan aman untuk ditemukan oleh anak usia dini. Adapun 20 jenis objek tersebut yaitu bowl, broom, bucket, calculator, cap, clock, dusbin, fan, flashlight, hanger, iron, keyboard, laptop, remote, scissors, spoon, stapler, teapot, thermos, dan toothbrush. Data dikumpulkan dari citra yang terdapat pada Google yang berukuran sekitar 255 x 255 dpi, dengan setiap objek terdiri dari 200 citra sehingga untuk keseluruhan data terdapat 4000 citra yang dibagi menjadi 3200 citra untuk data pelatihan dan 800 citra untuk data uji. Proses pelabelan dilakukan pada setiap citra yang berguna untuk mendapatkan ground truth bounding box yang menjadi acuan apakah terdapat objek pada citra tersebut.

\subsection{Pemilihan Arsitektur}

Parameter pada pengujian ini adalah epoch 50, batch 5, dan learning rate 0,004 . Hasil pengujian pre(1)rained model untuk mengetahui model terbaik yang cocok dengan dataset dapat dilihat pada Gambar 4.

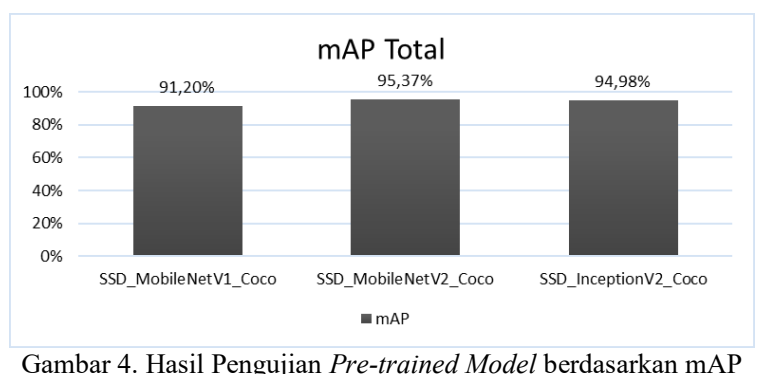

Gambar 4. Hasil Pengujian Pre-trained Model berdasarkan mAP Total

Hasil data pengujian pada Gambar 4 menunjukkan bahwa nilai pre-trained model SSD_MobileNetV2_Coco mendapatkan nilai mAP paling besar (yaitu 95,37\%) dibandingkan dengan SSD_InceptionV2_Coco yang memiliki nilai mAP 94,98\% dan SSD_MobileNetV1_Coco yang memiliki nilai mAP 91,20\%. MobileNetV $\overline{2}$ memiliki nilai mAP yang lebih baik daripada InceptionV2 dikarenakan MobileNet menggunakan konvolusi depthwise (3)separable yang memiliki jaringan konvolusi yang lebih mendalam dibandingkan InceptionV2 yang menggunakan konvolusi standar sehingga ini menghasilkan jumlah parameter yang lebih sedikit pada MobileNetV2 dibandingkan InceptionV2.

Sementara itu, MobileNetV1 memiliki nilai mAP yang rendah dibandingkan MobileNetV2 dikarenakan pada MobileNetV2 memiliki lapisan inverted residual bottleneck tambahan yang membuat MobileNetV2 akan memiliki lapisan konvolusi yang lebih banyak dibandingkan MobileNetV1, sehingga pada pelatihan MobileNetV2 membutuhkan waktu yang lebih lama 
dibandingkan MobileNetV1 bahkan waktu pelatihan InceptionV2 juga masih lebih lama dan hampir setara waktu pelatihannya dengan MobileNetV2 dibandingkan MobileNetV1 yang lebih cepat.

Tabel 1. Hasil Pengujian Parameter Epoch dan Learning rate

\begin{tabular}{cccc} 
No & Epoch & Learning Rate & mAP (\%) \\
\hline 1 & 50 & 0,04 & 83,99 \\
2 & 50 & 0,004 & 95,37 \\
3 & 50 & 0,0004 & 98,63 \\
4 & 100 & 0,04 & 97,73 \\
5 & 100 & 0,004 & 98,10 \\
6 & 100 & 0,0004 & 99,34 \\
\hline
\end{tabular}

\subsection{Pemilihan Parameter Epoch dan Learning Rate}

Berdasarkan hasil tahap pengujian pada subbagian 3.2, maka pre-trained model yang digunakan pada tahap pengujian ini adalah SSD_MobileNetV2_Coco. Selanjutnya dilakukan pengujian parameter epoch dan learning rate. Pengujian yang dilakukan menggunakan parameter epoch 50 dan 100, sedangkan learning rate menggunakan 0,04, 0,004, dan 0,0004 serta masih menggunakan batch 5 . Hasil pengujian parameter epoch dan learning rate terhadap nilai mAP dapat dilihat pada Tabel 1 .

Hasil eksperimen menunjukkan bahwa nilai epoch dan learning rate dapat berpengaruh pada tingkat akurasi. Maka dapat disimpulkan bahwa semakin besar nilai epoch maka semakin baik pula tingkat akurasinya, sedangkan jika semakin besar learning rate maka semakin buruk pula tingkat akurasinya dikarenakan ketelitian jaringan semakin berkurang yang disebabkan jaringan tersebut tidak stabil dan menyebabkan nilai error yang berulang pada nilai tertentu sehingga mencegah mencapai target yang diharapkan. Maka selanjutnya hasil pelatihan dari SSD_MobileNetV2_Coco dengan parameter epoch 100 dan learning rate 0,0004 digunakan pada implementasi model ke aplikasi android.

\subsection{Tahap Pengujian}

Pre-trained model yang digunakan pada tahap pengujian ini adalah SSD_MobileNetV2_Coco dengan parameter epoch 100 dan learning rate 0,0004 . Aplikasi berbasis android yang dibangun bertujuan untuk mengetahui hasil deteksi objek dengan berbagai sudut arah kamera yaitu depan, atas, kanan, dan kiri dengan latar putih. Sepuluh objek yang diujikan adalah bowl, clock, keyboard, remote, spoon, calculator, laptop, cap, stapler, dan thermos. Hasil pengujian pada aplikasi dapat dilihat pada Tabel 2 .

Hasil data pengujian pada Tabel 2 menunjukkan bahwa sudut arah kamera dari depan, atas, kiri dan kanan dapat mendeteksi hampir seluruh objek dengan latar putih. Maka berdasarkan hasil pengujian ini dapat dianalisis bahwa sudut arah kamera dari depan dapat mendeteksi seluruh objek dengan akurasi yang paling tinggi dibandingkan sudut arah kamera dari atas, kanan, dan kiri. Objek remote dan calculator memiliki karakteristik bentuk yang memiliki banyak tombol didepannya sehingga akan lebih sulit dideteksi selain dari arah depan sedangkan untuk objek spoon juga sulit dideteksi dari ketiga arah ini dikarenakan karakteristik bentuknya yang tipis dibandingkan dengan objek lainnya. Selain itu objek stapler tidak dapat dideteksi dari arah atas dikarenakan karakteristik bentuknya yang hampir sama hanya pada bagian depan, kanan dan kiri saja. Sehingga berdasarkan analisis pengujian tahap ini, dapat disimpulkan bahwa sudut pandang objek yang bervariasi pada dataset akan mempengaruhi hasil kinerja model dalam mengenali objek pada perangkat ponsel.

Tabel 2. Hasil Pengujian Object Detection Real-time

\begin{tabular}{|c|c|c|c|c|c|}
\hline No & Objek & $\begin{array}{c}\text { Deteksi } \\
\text { dari } \\
\text { Depan } \\
\text { (Score) }\end{array}$ & $\begin{array}{c}\text { Deteksi } \\
\text { dari } \\
\text { Atas } \\
\text { (Score) }\end{array}$ & $\begin{array}{c}\text { Deteksi } \\
\text { dari } \\
\text { Kanan } \\
\text { (Score) }\end{array}$ & $\begin{array}{c}\text { Deteks } \\
\text { i dari } \\
\text { Kiri } \\
\text { (Score) }\end{array}$ \\
\hline 1 & Bowl & $\begin{array}{c}\mathrm{Ya} \\
(0.96)\end{array}$ & $\begin{array}{c}\mathrm{Ya} \\
(0.80)\end{array}$ & $\begin{array}{c}\mathrm{Ya} \\
(0.89)\end{array}$ & $\begin{array}{c}\mathrm{Ya} \\
(0.87)\end{array}$ \\
\hline 2 & Spoon & $\begin{array}{c}\mathrm{Ya} \\
(0.93)\end{array}$ & $\begin{array}{c}\mathrm{Ya} \\
(0.79)\end{array}$ & $\begin{array}{c}\mathrm{Ya} \\
(0.70)\end{array}$ & $\begin{array}{c}\mathrm{Ya} \\
(0.78)\end{array}$ \\
\hline 3 & Clock & $\begin{array}{c}\mathrm{Ya} \\
(1.00)\end{array}$ & $\begin{array}{c}\mathrm{Ya} \\
(0.74)\end{array}$ & $\begin{array}{c}\mathrm{Ya} \\
(0.96)\end{array}$ & $\begin{array}{c}\mathrm{Ya} \\
(0.98)\end{array}$ \\
\hline 4 & Laptop & $\begin{array}{c}\mathrm{Ya} \\
(1.00)\end{array}$ & $\begin{array}{c}\mathrm{Ya} \\
(0.99)\end{array}$ & $\begin{array}{c}\mathrm{Ya} \\
(1.00)\end{array}$ & $\begin{array}{c}\mathrm{Ya} \\
(1.00)\end{array}$ \\
\hline 5 & Keyboard & $\begin{array}{c}\mathrm{Ya} \\
(0.99)\end{array}$ & $\begin{array}{c}\mathrm{Ya} \\
(0.86)\end{array}$ & $\begin{array}{c}\mathrm{Ya} \\
(0.99)\end{array}$ & $\begin{array}{c}\mathrm{Ya} \\
(0.99)\end{array}$ \\
\hline 6 & Remote & $\begin{array}{c}\mathrm{Ya} \\
(0.97)\end{array}$ & $\begin{array}{c}\mathrm{Ya} \\
(0.87)\end{array}$ & $\begin{array}{c}\mathrm{Ya} \\
(0.68)\end{array}$ & $\begin{array}{c}\mathrm{Ya} \\
(0.73)\end{array}$ \\
\hline 7 & Stapler & $\begin{array}{c}\mathrm{Ya} \\
(0,84)\end{array}$ & Tidak & $\begin{array}{c}\mathrm{Ya} \\
(0.89)\end{array}$ & $\begin{array}{c}\mathrm{Ya} \\
(0,83)\end{array}$ \\
\hline 8 & Thermos & $\begin{array}{c}\mathrm{Ya} \\
(0,99)\end{array}$ & $\begin{array}{c}\mathrm{Ya} \\
(0.98)\end{array}$ & $\begin{array}{c}\mathrm{Ya} \\
(0,96)\end{array}$ & $\begin{array}{c}\mathrm{Ya} \\
(0,91)\end{array}$ \\
\hline 9 & Calculator & $\begin{array}{c}\mathrm{Ya} \\
(0.94)\end{array}$ & $\begin{array}{c}\mathrm{Ya} \\
(0.87)\end{array}$ & $\begin{array}{c}\mathrm{Ya} \\
(0.85)\end{array}$ & $\begin{array}{c}\mathrm{Ya} \\
(0.89)\end{array}$ \\
\hline 10 & Hanger & $\begin{array}{c}\mathrm{Ya} \\
(0.99)\end{array}$ & $\begin{array}{c}\mathrm{Ya} \\
(0.88)\end{array}$ & $\begin{array}{c}\mathrm{Ya} \\
(0.99)\end{array}$ & $\begin{array}{c}\mathrm{Ya} \\
(0.99)\end{array}$ \\
\hline
\end{tabular}

\subsection{Pengujian Aplikasi Edukasi Anak Usia Dini}

dalam Mengenali Objek

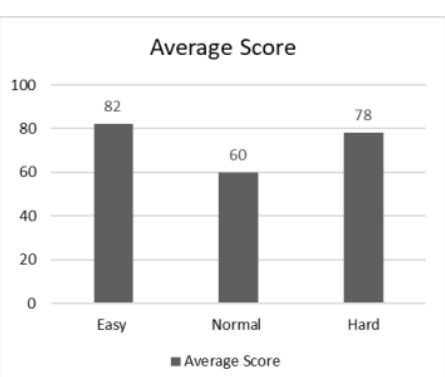

Gambar 5. Hasil rata-rata skor pengujian aplikasi pada anak-anak

Pengujian aplikasi edukasi anak usia dini dalam mengenali objek dilakukan dengan penggunaan aplikasi secara langsung pada 25 anak usia dini. Hasil pengujian aplikasi edukasi anak usia dini dalam mengenali objek dapat dilihat pada Gambar 5 dan Gambar 6. Sepuluh orang anak mencoba tipe soal easy, 5 (lima) anak mencoba tipe soal normal, dan 11 anak mencoba tipe soal hard. Rata-rata skor untuk tipe 
soal easy adalah 82, untuk tipe soal normal adalah 60 , dan untuk tipe soal hard adalah 78 .

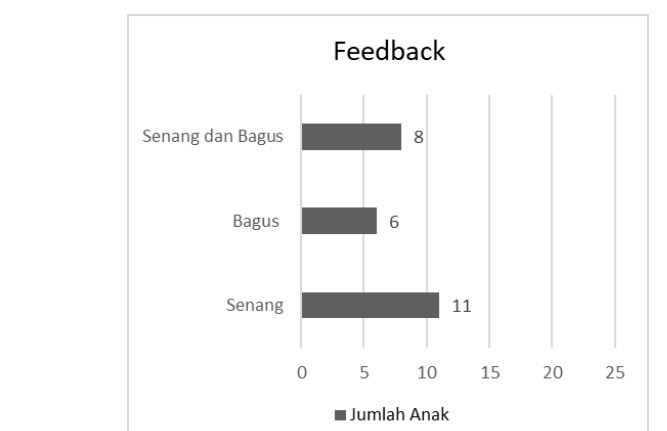

Gambar 6. Hasil feedback pengujian aplikasi pada anak-anak

Feedback dari pengguna terkait aplikasi dikumpulkan dengan memberikan 2 (dua) pertanyaan yaitu (1) apakah pengguna merasa senang saat menggunakan aplikasi dan (2) apakah pengguna merasa aplikasi ini bagus. Hasilnya menunjukkan bahwa 8 pengguna merasa senang dan menilai aplikasinya bagus, 11 merasa hanya senang, dan 6 merasa aplikasi hanya bagus. Maka berdasarkan hasil pengujian ini dapat dianalisis bahwa anak usia dini sangat tertarik dengan tipe soal yang menampilkan gambar dibandingkan tulisan dan anak usia dini dapat mendapatkan hasil score antara 80 atau 90 untuk tipe soal bergambar dibandingkan dengan tipe soal tulisan. Sedangkan ketertarikan anak usia dini dengan aplikasi edukasi ini menampilkan reaksi yang antusias selama simulasi di mana feedback dari anak usia dini memberikan respon yang positif yaitu merasa senang ataupun bagus terkait aplikasinya. Berdasarkan eksperimen yang dilakukan, dapat ditunjukkan bahwa aplikasi yang dibangun dapat diaplikasikan pada penggunaan yang lebih luas, yaitu untuk memberikan edukasi penggunaan ponsel yang baik kepada anak usia dini dengan cara mengenalkan objek-objek yang terdapat di lingkungan sekitarnya.

\section{KESIMPULAN}

Pada penelitian ini, kami mencoba mengimplementasikan model MobileNet yang telah dilatih pada $C O C O$ dataset yang memiliki 91 kelas objek dan diaplikasikan transfer learning pada dataset baru yaitu 20 kelas objek. Dari eksperimen yang dilakukan, kami mendapatkan hasil nilai mAP sebesar 99,34\% menggunakan pre-trained model pada arsitektur SSD MobileNetV2 Coco dengan parameter epoch $10 \overline{0}$, learning rate 0,0004 , dan batch 5. Sedangkan hasil simulasi aplikasi edukasi ini menunjukkan bahwa anak usia dini antusias dengan kehadiran aplikasi ini dengan memberikan feedback yang positif dikarenakan aplikasi ini memberikan metode pembelajaran yang lebih interaktif apalagi menggunakan media ponsel yang digemari anak usia dini pada saat ini.

Namun pada aplikasi edukasi ini masih memiliki kekurangan dalam mengenali objek terutama pada faktor background environment dan viewpoint yang menyebabkan aplikasi mengalami kesulitan dalam mengenali objek dengan kedua faktor tersebut. Oleh karena itu, untuk penelitian lebih lanjut disarankan agar menambah dataset yang lebih bervariasi dengan latar objek yang berbeda ataupun sudut pandang objek yang berbeda pada setiap citra agar dapat mengatasi objek dengan background environment dan viewpoint yang berbeda-beda. Dan juga dapat mencoba pretrained model yang lebih besar seperti dataset ImageNet yang memiliki 1000 kelas sehingga sistem dapat digunakan untuk mengenali berbagai macam kelas objek selain 91 kelas objek yang ada pada $\mathrm{COCO}$ dataset.

\section{DAFTAR PUSTAKA}

DU, C.J., CHENG, Q., 2014. Computer Vision. In: O'Donnell C., Fagan C., Cullen P. (eds) Process Analytical Technology for the Food Industry. Food Engineering Series. Springer, New York, NY.

HADDON, L., 2013. Mobile media and children. Mob. Media Commun.

HENDERSON, P. dan FERRARI, V. 2017. End-toend training of object class detectors for mean average precision. Lecture Notes in Computer Science (including subseries Lecture Notes in Artificial Intelligence and Lecture Notes in Bioinformatics)

HOWARD, A. G. dkk., 2017. MobileNets: Efficient Convolutional Neural Networks for Mobile Vision Applications. ArXiv.

HOSANG, J., BENENSON, R., AND SCHIELE, B., 2017. Learning non-maximum suppression. Proceedings - 30th IEEE Conference on Computer Vision and Pattern Recognition, CVPR.

HUA, B., TRAN, M.-K, AND YEUNG, S.-K., 2018. Pointwise Convolutional Neural Networks. Cvpr.

LIN, T. Y. dkk, 2014. Microsoft COCO: Common objects in context. Lecture Notes in Computer Science (including subseries Lecture Notes in Artificial Intelligence and Lecture Notes in Bioinformatics)

LIU, W. dkk, 2016. SSD: Single shot multibox detector. Lecture Notes in Computer Science (including subseries Lecture Notes in Artificial Intelligence and Lecture Notes in Bioinformatics).

PAN, S. J. dan YANG, Q. 2010. A survey on transfer learning. IEEE Transactions on Knowledge and Data Engineering.

ROSENBROCK, A., 2017. Intersection over Union (IoU) for object detection. Pyimagesearch.com.

SANDLER, M., ZHU, M., ZHMOGINOV, A. dan JAN, C.V., 2018. Inverted Residuals and Linear Bottlenecks: Mobile Networks for Classification, Detection and Segmentation. 
CVPR

SANDLER, M., HOWARD, A., ZHU, M., ZHMOGINOV, A. dan CHEN, L. C., 2018. MobileNetV2: Inverted Residuals and Linear Bottlenecks. Proceedings of the IEEE Computer Society Conference on Computer Vision and Pattern Recognition.

SZEGEDY, C., VANHOUCKE, V., IOFFE, S., SHLENS, J., dan WOJNA, Z., 2016. Rethinking the Inception Architecture for Computer Vision. Proceedings of the IEEE Computer Society Conference on Computer Vision and Pattern Recognition, pp. 28182826

WANG, G., YUAN, G., LI, T. dkk, 2018. An multiscale learning network with depthwise separable convolutions. IPSJ T Comput Vis Appl 10 (11). 
Halaman ini sengaja dikosongkan 